\title{
LITERARY GEOGRAPHY AND CULTURAL TRANSLATION
}

\section{EVA-NICOLETA BURDUȘEL}

Universitatea „Lucian Blaga” din Sibiu

Acknowledgement: This work was supported by a grant of the Romanian Ministry of Research and Innovation, CCCDI - UEFISCDI, project number PN-III-P1-1.2-PCCDI-2017-0821/ INTELLIT, within PNCDI III

„Most people are principally aware of one culture, one setting, one home

(Edward Said - "Reflections on Exile and Other Essays. Convergences: Inventories of the Present")

"A good place to understand the present and to ask questions about the future, is on the ground, travelling as slowly as possible." (Robert Kaplan - "The Revenge of Geography")

The paper aims to highlight and illustrate some recent shifting paradigms in the cultural context with an impact on the literary production, based on recent theories in the areas of cultural geography, mind mapping, cultural translation, and literary landscape. The role of humanities nowadays shall also be examined, given the age-old debate over culture and science, or mind versus matter following the pattern of cyclical changes or wave-like movements in history.

In between the two significant and relevant mottos, serving as a harbinger to the present study and its scholarly goal, literatures creates a cultural map of the world, as a genuine pontifex, enabling the individual, at home in his own native culture with a particular tradition, history, language, to travel the world by means of stories, slowly from one end of the world to another, thus rendering a polyphonic view of the world, a multicultural network of human experience. 
Literature is shaped not only by language and culture, but equally so by the interdependent relation of history, geography and politics which shape the substance of a text, appealing to the mind of the reader by satisfying the curiosity in the human desire to demythicize the unfamiliar and find out more about the world from other people`s stories. E. M. Forster`s well known phrase "only connect" is most expressive and reflective of the need to communicate through culture, as well as to connect the opposites.

A literary text emerges and bears the imprint of a territory which is also perceived as complex context made up of cultural, geographical and historical dimensions, with both an internal and external identity. "History is the offspring of geography, whereas politics is the offspring of history", moreover "history is usually what people make of it ... often, factual reality is overtaken by a parallel reality of perceptions."

In the empirical understanding and scholarly analysis of literature, maps prove to be a fundamental instrument in view of attaining an accurate and comprehensive view of the literature of the world and an essential tool in approaching the huge amount of literary production. In this context, reference shall be made to two different definitions of maps: one was set forth by Franco Moretti and operates as a vector in the correlation of literature and geography:

An atlas of the novel. Behind these words, lies a very simple idea: that geography is not an inert container, is not a box where cultural history 'happens' but an active force, that pervades the literary field and shapes it in depth. Making the connection between geography and literature explicit, then - mapping it: because a map is precisely that, a connection made visible - will allow us to see some significant relationships that have so far excaped us. Sucha literary geography can refer to two very different things. It may indicate the study of space in literature, or else, of literature in space ... the distinction between the two spaces ... is based on the systematic use of maps ... not as metaphors ... but as analytical tools: that dissect the text in an unusual way, bringing to light relations that would otherwise remain hidden. A good map is worth a thousand words, cartographers say ... What do literary maps allow us to see? Two things, basically. First, they they highlight the place-bound nature of literary forms ... and then, maps bring to light the internal logic of narrative ... Literary form appears thus and the result of two conflicting and equally significant forces: one working from the outside, and one from the inside. It is the usual, and at the bottom the only real issue of literary history: society, rhetoric and their interaction. ${ }^{2}$

1. Dmitri Trenin, The End of Eurasia, 2002, p. 29

2. Franco Moretti, Atlas of the European Novel: 1800-1900, London, New York: Verso. 1999, 3,5 
Furthermore, the concept of cultural geography can be employed at several levels: one of them concerns the interpretation of a literary text which is embedded in a cultural and geographical context, hence the value of a literary product is intertwined and imbued with cultural geography; the other meaning and relevance of cultural geography in the area of literature refers to the horizontal and vertical divisions of the literary market, as defined by Franco Moretti. Literary geography highlights another division: that between the centre and the periphery, emerging from power relations, and affecting both the literary market and the evolution of literary genres.

The other definition of maps is a more subjective one and it is closer to what is commonly and euphemistically called fiction, where mental maps provide a selective view of the world based on the individual framework relying on a biased perception of inhabited geographical areas, meant to renew and strengthen pre-established polarities: "To portray meaningful relationships for a three-dimensional world on a flat sheet of paper or a video screen, a map must distort reality ... There`s no escape from the cartographic paradox: to present a useful and truthful picture, an accurate map must tell white lies."

"Mental maps" is a phrase launched and explained by Jaap van Ginneken

The first [mechanism] concerns centrality. There is a tendency to place one's own country in a central position, at least, in a more central position than it would be in others' maps and to group the rest of the world around it. Simultaneously, there is a tendency to make other countries and, indeed, entire continents peripheral ... The second mechanism concerns volume. There is a tendency to enlarge the surface of one's own country, to inflate it disproportionately in comparison to others. Simultaneously, there is a tendency to deflate other areas considered as irrelevant. The third mechanism concerns articulation. There is a tendency to render one`s own country in great and characteristic detail, and to reduce other countries and continents to shapeless blobs. On the one hand, this is a very 'logical' result. On the other hand, it also betrays the collective narcissism in which we are all imbued. ${ }^{4}$

The mobility and exchange of travelling theories and ideas is not only essential to the creation of a global intellectual network but it also enables both the awareness of perception and understanding between the centre and the periphery as well as re-shaping and adaptation of conceptual concepts, framework and ideologies according to the particular socio-cultural contexts and reflected in the literary productions. Similar to literary genres and the

3. Jaap van Ginneken, J., Understanding Global News, London, Sage Publications, 2009, p.4 4. Jaap van Ginneken, J., Understanding Global News, London, Sage Publications, 2009, p.5 
related works which travel the world, storytelling enables the performance of cultural empathy among human being, therefore literature and culture connect people and places; highlighting the interdependence between art and context - viewed as geographical territory, literary area, space vs. place, in addition to the notion of individual and collective stance in society. Literature empowers people, either at the centre or the periphery, to travel the world by means of narrative imagination, to have access to and knowledge about any part of the world notwithstanding physical distance and relate to the universal matters of the human being. ${ }^{5}$

Our goal is to highlight the cultural component of literary translation, to emphasize the relevance of the human dimension in the process of translation as a prerequisite addition to digital translation tools. Language is the foundation of culture, it is the lively, dynamic and incessantly changing component of the historical evolution of a nation. The reciprocal interaction between language and culture ensure the continuity and survival of nation-states and the people inhabiting geographical territories, particularly in a context marked by a paradoxical interaction between autonomy and dominance.

The relation of language to culture is that of part to whole." (Goodenough, "Cultural Anthropology and Linguistics" qtd in R.A.Hudson, Sociolinguistics, Cambridge University Press, 2004, p. 79) or in the field of translation studies, the widely acclaimed Umberto Eco`s Experiences in Translation reinforcing the idea that " ... translation is always a shift, not between two languages, but between two cultures - or two encyclopedias." ${ }^{\prime}$

Reputed translation theorist Susan Bassnett highlights that language is "the heart within the body of culture, and that it is the interaction between the two that results in the continuation of life-energy" closely related to the theses of Edward Sapir, Benjamin Lee Whorf and Juri Lotman according to which "no language can exist unless it is steeped in the context of culture; and no culture can exist which does not have at its center, the structure of natural language." (qtd in Bassnett, 22). ${ }^{8}$

Emily Apter in her highly informative study "The Translation Zone" called attention to the significance of the translation process, its challenges and complexity, evinced by the paradoxical balance between "nothing is translatable" and "everything is translatable" emphasizing the power of the

5. Eva-Nicoleta Burdusel, Cultural Diplomacy. Literary Representations of Soft Power and Smart Power. Tradition and Modernity, Revista Transilvania, nr 11-12/2018

6. U. Eco, Experiences in Translation, University of Toronto Press, 2001, p. 17

7. Susan Bassnett, Traslation Studies, 22

8. Eva-Nicoleta Burdusel, Literature and Multiculturalism. Connecting Cultures and Mapping the World through Storytelling, Revista Transilvania, nr 9/2017 
word to acquire meaning in a given cultural context demanding the ability of the audience, reader, recipient to decode and decipher the intended meaning in addition to the skill and wit of the translator to render and adapt the word and its attached meaning to the target culture. The transfer of linguistic meaning and cultural significance is a transactional process and literature is deeply impacted by translation in several ways: translated literature become a source of artistic inspiration and influence for writers as they get familiar with the development literary genres in other cultural contexts, translated literature came to be regarded as a source of information due to the stories that travelled the world performing the role of common denominator for the experiences of humankind worldwide, where literature has the unique power to endow individual existence and experience with universal value and enduring power, as highlighted by the Nobel Prize for Literature, for instance, testifying that the emotions and experience of human beings are very similar despite any geographical distance or cultural difference. Literary awards are highly reflective of the international circulation of works of art, where translation is the fundamental vehicle for the dissemination of stories as an embodiment of human experience and a vector for the achievement of worldwide fame. Literature performs another important role: it may turn our attention, preoccupation, interest from external experience to our inner life of the mind and soul.

Furthermore, quantitative studies prove relevant not only for an analysis of the evolution of literary genres, but even more so in the case of translation where the construction of databases is an ongoing linguistic and cultural process, a lively phenomenon rooted in previous versions and resources and equally looking ahead to new meanings and updated usage. Parallel with the technological advancement and the creation of terminology databases, the human dimension will always prevail in the translation process and all other technical facilities and specialized software will rank secondary and auxiliary to the equally creative and thought-provoking processes of the mind.

To conclude, digital humanities and cultural translations are fields that merge well in an interdisciplinary endeavour at reviving the process of scholarly reading, interpreting and translating. 


\section{Bibliography:}

1. Dmitri Trenin, The End of Eurasia, 2002, 29

2. Franco Moretti, Atlas of the European Novel: 1800-1900, London, New York: Verso. 1999, 3,5

3. Jaap van Ginneken, J., Understanding Global News, London, Sage Publications. 2009,4

4. Jaap van Ginneken, J., Understanding Global News, London, Sage Publications. 2009,5

5. Eva-Nicoleta Burdusel, Cultural Diplomacy. Literary Representations of Soft Power and Smart Power. Tradition and Modernity, Revista Transilvania, nr 11-12/2018

6. U. Eco, Experiences in Translation, University of Toronto Press, 2001, 17

7. Susan Bassnett, Traslation Studies, 22

8. Eva-Nicoleta Burdusel, Literature and Multiculturalism. Connecting Cultures and Mapping the World through Storytelling, Revista Transilvania, nr 9/2017 